\title{
The Review
}

\section{The Leonardo Grant:}

\author{
an opportunity to undertake a Hippokrates Exchange Programme
}

The Hippokrates Exchange Programme allows GPs in training or first5 GPs to visit one of a number of European countries to observe general practice. It aims to promote mobility of young GPs, providing a broader perspective of primary care. The Leonardo grant is a competitive European Union grant for lifelong learning secured by the RCGP's Junior International Committee (JIC) to fund participation in the Hippokrates Exchange Programme.

In September 2011, the Leonardo grant allowed me to participate in a 2-week Hippokrates exchange to Krakow, Poland (picture below). Krakow is a beautiful city in southern Poland famous for its medieval architecture, academic heritage (Copernicus studied at Jagiellonian Universityl, and the infamous holocaust story of Schindler's List. The exchange programme gave me a unique experience delving beneath the touristic veneer and have a brief glance at real Krakovian life. I spent 2 weeks between three practices in the city of Krakow shadowing three GPs and one GP registrar.

The main practice at which I was based was in Kazimierz, the old Jewish quarter of Krakow and an up-and-coming popular area. The practice however catered mainly for the traditional working class residents of the area, an older and almost exclusively Polish population. It was affiliated with Jagiellonian University and owned by senior doctors in the practice. The GP I observed worked as a salaried employee. Family

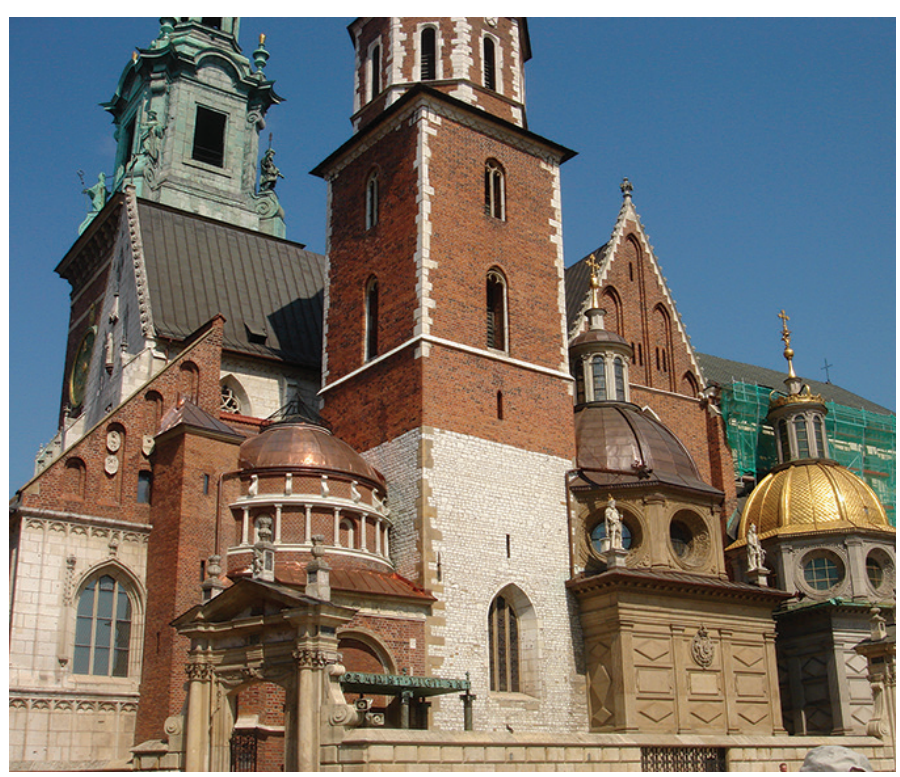

practices in Poland receive a per capita payment for children and older patients. There are also additional payments for managing specific chronic diseases. I saw a similar array of cases familiar to UK general practice.

General practice lor family medicine as it is known in Poland) has only been recognised as a speciality since 1995 . experienced firsthand the possibilities afforded by the speciality's youth, but it also helped me appreciate the longevity of general practice in the UK. On the upside there is a real passion for research into and development of the speciality, and training is flexible, includes early GP exposure, lasts for 4 years, and has a good balance between primary and secondary care. On the downside Polish general practice has yet to develop the respect from other specialties, infrastructure, and support that it receives in the UK. In addition, attracting top quality trainees in competition with other specialties was highlighted as a problem. Direct access to certain specialities in Poland makes the role of the GP as a gatekeeper somewhat defunct and I experienced the problems with patient care that directly result from this. A particular highlight for me was the opportunity to observe the teaching of international (Norwegian and British) medical students in the English language stream at Jagiellonian University. This gave me an insight into English language training outside English speaking countries.

Observing general practice in Poland showed me that the UK way is not the only way. It gave me new enthusiasm for the speciality and the opportunity to meet inspirational GPs working in a different setting. I now have a better understanding of the healthcare system that my Polish patients are used to which helps put their complaints in context. A Dzień

\section{ADDRESS FOR CORRESPONDENCE}

\section{Hannah Willoughby}

Department of Postgraduate Medical and Dental Education, 8th Floor, Neuadd Meirionnydd, Heath Park, Cardiff, CF14 4YS, UK.

\section{E-mail: hannahwilloughby2002dyahoo.co.uk}

\section{dobryalso goes down well.}

Hosting a visitor can be an equally rewarding experience. Hosting provides an opportunity to share your passion for general practice with someone equally as enthusiastic. Learning about health care in your visitor's country offers the opportunity to reflect upon your own clinical practice and healthcare system, to appreciate the facilities and system that we have and to think about developing new ways to improve clinical practice and patient care.

Interested in visiting Poland or elsewhere through a Leonardo funded Hippokrates exchange? Good news! In August 2012 the next round of applications for Leonardo funding was launched. For more information and application forms contact your local faculty, visit our Facebook page, or this link: http://www.rcgp.org.uk/international/ services_we_provide/junior_international_ committee.aspx.

Thirty-five successful applicants will be awarded a grant to cover travel costs, living expenses, and language courses involved with a 2-week exchange. After a preparatory period, exchanges will take place in 2013. Participants will also be asked to host a visitor from another European country.

\section{Hannah Willoughby,}

JIC Deputy Exchange Lead, Academic GP Trainee, RCGP Junior International Committee, and

Department of Postgraduate Medical and Dental Education, Cardiff University.

\section{Victoria Welsh,}

GP, NHS North Staffordshire, Deputy Research Lead JIC.

\section{Madeleine Attridge,}

Academic Fellow, Cochraine Institute of Primary Care and Public Health, Cardiff University, Exchange Lead JIC.

\section{Robin Ramsay}

GP, Eglin, Morayshire, Chair JIC. 